\title{
Aesthetics and Nature: A Preface
}

\author{
Can Xue
}

When I wrote down the title, I recalled the original intention of my conversation with my brother Xiaomang. It was in the August of 2009 when concepts about aesthetic activity in my mind were still very vague. My aesthetic activities in the past thirty years brought me rich experiences, and I am deeply aware of the roles some $a$ priori principles play in my creative practices. Also, the literary criticism I wrote in the past years all reflected these principles. However, I have never had a comprehensive summary of all these experiences, nor have I elevated them to a purely theoretical level. Like something unexpected, or a fated coincidence, Xiaomang's accomplishments in the fields of philosophy and aesthetics made it possible for us to have a common breakthrough. His highly theoretical foresight and profound understanding of Western classical philosophy and aesthetics, as well as his original, insightful, and unique views, all have laid a deep and solid foundation for our conversation. ${ }^{1}$

For many years, I have realized that an a priori mechanism always operates in my aesthetic activity. First, this mechanism dominates my creative writing. Then, for more than fifteen years, it has also dominated my literary criticism. Its functions demonstrate some similarities and differences between these two sorts of exercises. Xiaomang and I repeatedly discussed this mechanism in our conversations, which we now call the syncretic aesthetic mechanism of Logos and Nous, a mechanism of a high level self-consciousness of human beings. It includes the following key words: emotional experience, self-consciousness, intellectual intuition, reflective application, split, transcendental unity of apperception, vertical communication, essence, aesthetic levels, and so forth.

This year I started an intensive reading of Kant's The Three Critiques and realized that I greatly benefitted from such a reading. In his era, Kant's mode of thinking stimulated a revolution in the field of thought much like Copernicus's. This, for the first time, changed Nature into the Nature of human beings and established the dynamic role of subjectivity. I feel that the fields of literature, art, aesthetics, and philosophy today also need such a reformation, and I have seen a possibility for this reformation. Most of my spiritual nutrition came from Western literature and the arts. Perhaps because I am an artist with strong rationality (here by saying "rationality" I mean "self-consciousness"), and at the same time, because I am deeply rooted in Eastern culture, I have a unique vision of Western literature. This may be what previous Chinese and foreign writers were lacking. I am eager to tell my readers what I know, to endow them with such a vision, which would enable them, through exercises, to shake off the fetters of convention and to attain the kernel of literature and art.

I think that basically Kant's spirit coincides with my literary creation. He stresses the dynamic role of

\footnotetext{
${ }^{1}$ I want to thank Jonathan Griffith for his meticulous editing of the translation. I am also grateful that Can Xue read through my draft several times. She corrected some errors and provided me with suggestions for revisions.
} 
subjectivity and the reflective capability of an individual as a human being. My kind of literary creation cannot depart from such a spirit even for a moment. However, through our conversation, Xiaomang and I reached an identical view that some aspects in the aesthetic theories of Kant and other thinkers cannot fit the needs of the current age any more. Literature and art continuously develop and raise new questions to our era. Furthermore, theories of literature and art, together with literature and art themselves, should be fused with philosophy as a spiritual phenomenon, and then become the most essential part in practical philosophy. Kant holds that humans become the final end of Nature because of morality; by contrast, we think that humans become human because of life consciousness. Moreover, in the process of practicing and understanding life consciousness, aesthetics is the most fundamental activity. This is, of course, a high standard, but it is also the cognitive mission Nature entrusts to human beings. Such a type of understanding is not a set mechanism, but a sort of rational understanding, that is, it re-constructs experience with reflective approaches, just as Copernicus did in his time. The tendency of contemporary art in the world and the spirit of the present age are exactly grounded in reflection. The realm of the rational understanding (including moral consciousness) is not only the sphere of the spiritual world of human beings, but also the essential realm of Nature. Yet, aesthetic understanding is the core of that essence.

No other cognition is more dynamic and capable of stimulating life force than aesthetic understanding. In aesthetic understanding, the key words are performance and reflective exploration in depth, as well as risky existence. Aren't they the essence of life? Hence, aesthetics is the highest level of instinct and also the basic activity motivating human nature to develop toward an ultimate good. For this reason, humans are distinct from animals. We can say that aesthetic judgment is self-consciousness itself. Its laws are subject to the principles of rational unity of apperception, that is, the highest laws. In Kant's era, perhaps philosophers had not been aware of this point. However, today, repeated practices by many top-level artists have projected this structure of reflective understanding, which should be a completely new and pioneering apprehension that we humans have of ourselves and of Nature in which we abide, as well as a manifestation of the spirit of our time. This is to say, philosophical knowledge is combined with aesthetic understanding to be a higher-level theory of rational understanding. The rational practical understanding moves in a reverse direction toward a breakthrough of our spiritual world. A general view is that the innate world of one's heart is a small world. However, few people really understand that this small world, with limitless layers, has pure spiritual logic and laws, and furthermore, leads to an immense world that is much larger than "the external world" we usually refer to, which can endlessly expand along with our cognition. I have the feeling that the contemporary spirit will develop by leaps and bounds toward this direction. When I practice such an aesthetic activity, there occurs in my mind a certain kind of ineffable abstract realm, which touches myself deeply. In my view, that realm is an ultimate and beautiful idea, which may be similar to philosophical ideas, but probably more emotional. Although having emotional colors, it is not equal to the "ideal" in Hegel's sense. Instead, it is an actual concept because it is a highly abstract poetic idea that excludes all that is concrete and empirical. It is also "the Beautiful” that we artists long for day and night. Maybe only such an epistemology could adapt to the mystery of human nature and the mystery of Nature (with which we are confronted), and make it possible for us to re-unify the deconstructed world, and to re-establish life activities as purposeful practices.

The mechanism of aesthetics is exactly the mechanism of human nature; it is also a mechanism for human beings to know the self and Nature; furthermore, it is a mechanism that leads to the realization of the most 
fundamental part in the life experience of human beings. Primarily shaping this mechanism in the ontological entity of humans - from the perspective of objective teleology — Nature molds an individual with such a faculty of understanding in order to realize its essence through human beings - for the purpose of operating itself in the life activities of human beings. This mechanism has a special feature, that is, it starts in communication, and then operates its roles. Therefore, its initiation and operation need the highest dynamic role of subjectivity and frequent communicative activities as its motivation. In this sense, it is completely subject to subjective activities of human beings, as well as interactive communication amongst people.

The creation and appreciation of modern art have already internalized and profoundly reflected upon the communicative experience amongst people. In aesthetic activities, experience is not the application of sensational intuition any more, but rises to be the application of intellectual intuition. Yet, undoubtedly, creation and appreciation still take these communicative experiences as motivation indirectly. However, the new type of aesthetics has a transcendental nature. In aesthetic activities, artists and appreciators, based on communication amongst people, elevate communication to something between human beings and Nature in order to realize the essence of Nature. Once an aesthetic judgment starts, the a priori mechanism of contradiction in the subject transforms one's existent emotional experience into a deeper level of the self, and makes each part of the self perform in a both splitting and unified way. Such a reflective application of experience is very difficult and creative, which re-constructs the small nature of "the self." This process de-familiarizes the self and reveals the nature of the self, which enables human nature to fully demonstrate the beauty of freedom. In addition, in this process, the subject will strongly feel the will of Nature-the objective will that is inherent in one's self; that is, the communication between human beings and Nature. It is realized through humans' pursuit of freedom and the ultimate beauty. Human beings have to break through the limits of our physical body (sensational intuition) to leap to a deeper essence of the self (which is recognized through intellectual intuition), that is, the essence of Nature. As a result, the innate mechanism is initiated in such continually repeated free operations, which is the same for both creation and appreciation.

Only communication amongst humans is reflective. From the very beginning, primitive humans eagerly intended to see the self in the other, which is actually an earnest tendency to understand the essence of Nature. In the development of aesthetic history, this reflective tendency has become stronger and stronger, and its latent structure emerged. Nowadays, based upon the practice by their forerunners, a small number of artists, who are the most sensitive, have, through aesthetic activities, been made aware of one's spiritual level, the union of one's self with Nature, as well as humans' lofty mission of understanding. However, this type of advanced communication is still grounded in secular communicative activities that promote the formation of the spiritual level. Those who can be engaged with such aesthetic activities are rich and complicated in their inner heart, able to have an insight into the heart, and have a deep love of life. They conceal their ordinary life experience in their hearts, savor it again and again, and then, under the operation of the mechanism, make it produce a breakthrough with intellectual intuition, in order to re-construct the self and to demonstrate the beauty of the essence of Nature. From this we can even have a reverse assumption that the essence of Nature is freedom, because we have already repeatedly made experiments in our innate small nature, and because our works also fully reflect the responses of the grand Nature to our innate small nature. The objectivity of the mechanism that we sense in our creation or appreciation is the objectivity of Nature, which forces our aesthetic senses to take shape, and then to demonstrate 
in our own works a panoramic picture of our ultimate pursuits. When we reveal the mechanism in a piece of work through appreciation and analysis, we are unified with Nature. The Beautiful is to realize the communion between humans and Nature through the communication among people in interactions. The most profound thing is that the activity is a reflective creation, within which sensational intuition cannot immediately play a role. Instead, all experiences from life have to be deepened and re-created to become intellectual intuition, with which one can construct the beauty of rationality and freedom. Therefore, those who are engaged in artistic activities (including appreciators) should be deeply involved in a secular life, but at the same time, have the ability of intellectual intuition to make such a life abstract so as to penetrate into its essence. Nature provides this ability for very few individuals who are extremely sensitive to spiritual matters; however, exercises and deep engagements in life are the prerequisites for this type of aesthetic judgment.

To modern artists, what is inspiration? It is the ability to identify in creation or appreciation the materials for intellectual intuition. Through the operation of our innate mechanism, we find in our small nature the new usages of our empirical materials, and we want to make a completely new thing out of them. This is our inspiration. In other words, not only does the attainment of inspiration need to have rich and multiple levels of emotional experience, but it also requires immense reflective power in our heart. Only when both rationality and emotion are available, can aesthetic judgment happen. Such aesthetic judgment is not an imitation of Nature, but a discovery of Nature, and a creation and re-construction of Nature. All artistic products (including products of appreciation) are merely products of Nature itself. Nature creates and re-constructs itself through human beings. This is identical with the discovery of scientific rules: both are creation and re-construction of Nature by means of reflective judgment. The operation of inspiration coming from intellectual intuition is opposite to that of inspiration coming from sensational intuition. The former is to transform emotion that has been made abstract into dissimilated senses for constituting beautiful products; the latter is to collect the directly sprouting emotion and represent it in surface memory so as to form a piece of artwork. But psychology cannot explain the reflective application of aesthetic activity to memory, which belongs to humans' creative cultivation of a priori abilities of the self, and is imbued with the initiation of spiritual activities. This can only be explained by the science of spirit itself, that is, aesthetics or artistic philosophy.

Then, how can we specifically conduct reflective aesthetic practice? The key word should be exercise. Nature endows us with this capability, but the conditions she sets up are very harsh. We are unable to employ it easily. Only those who have a sensitive nature and are full of curiosity about spiritual matters and passion for exploration can, after years and years of innumerable difficult exercises, obtain the capability of intellectual intuition. Such capability enables one to make one's experiences to be formed into a design by the mechanism so as to construct a great variety of pictures of human nature with ultimate beauty-that is, pictures of Nature. In the process of creation, the artist is surrounded by daily emotional experiences, but is also independent of them when gazing at them. What one sees in meditation is not the superficial meaning of experience, but how one's innate deep mechanism operates in experience. The artist needs to use the mechanism to change disordered experience into regular structured pictures with the essential beauty. One sets out one's energy, and one's rebellious nature makes one do whatever one likes, which is exactly required by the mechanism. This is because an artist has to produce something that has never been existent. An artist does not aim to experience the past, but to create the future, to attain new and transcendental emotional experience. Transcendental impulses impel an artist to return 
to old primitive memories of human beings, that is, Nature, so as to re-create Nature. Someone who appreciates a work of art can also have a similar, reverse experience. With a piece of artistic work in front of one's eyes, one gazes at it, and sees one's performance of "viewing" in a long time of gazing. At that moment, the special structure of the artistic work will gradually emerge toward one's aesthetic judgment, which is completely a result of interaction between the work and the appreciator. If an appreciator does not have such an inner mechanism, or does not use the mechanism to trigger emotional experience, then the Beautiful will not occur between the viewer and the work; instead, it will be hidden in clouds and fog. Therefore, if you attempt to appreciate superior artistic works, you have to continually drill and continually strengthen your inner mechanism in order to initiate it again and again, during which it can be combined with free information conveyed by the work. At the same time, the experience in your heart will also participate in communication and re-construct your own self and nature. This kind of successful appreciation is not a bit easier than creation, and is maybe even more difficult. That is why even today few people can reach the deeper meanings of numerous ancient classics.

How can we prove that an artistic creation can communicate with Nature? From the perspective of artists, only when other people or they themselves reveal through aesthetic activity the structure determined by that innate mechanism, can people truly appreciate their artistic works. The process of revelation is a complicated interaction. However, once the structure emerges, we can see the pictures of human life activities in great depth. And accordingly, a variety of imagery of human efforts to transcend and to vertically communicate with Nature will also occur everywhere. It also occurs that this is deeply grounded in emotional experience among people. Hence, it becomes clear that modern art is by no means a daydreaming that is separate from a worldly life of human beings. What it needs is the stability and creative power of the heart. When I judge if a piece of work has a deep level of aesthetic value, I usually observe if it has that structure, if it makes reflective use of emotional experience, and if intellectual intuition is manifested in the unity of the work. From the perspective of appreciators, they need to take up a double obligation—not only conveying an author's self and Nature, but also transforming their own selves into Nature. In so doing, they re-construct the author's nature. Therefore, successful appreciation is a synthetic re-creation. The number of appreciators will determine how many ways of re-creation there could be. But no variation departs from its origin: all products of appreciation express an ideal of freedom, that is, the ideal that Nature and human beings become one.

In addition, I want to emphasize that the aesthetic activities we have discussed have an ultimate objectivity. Humans can perceive aesthetics from the stance of Nature, not just from the stance of humans. This point is neither the same as Kant's, nor Hegel's. Kant views the Beautiful as a product of pure subjectivity and denies any cognitive meaning of aesthetic judgment. Hegel is one step further than Kant by holding that art contains a subjective objectivity. Nevertheless, the objectivity he refers to lacks layers and is thus a differentiation that is rigid and confined to the social nature of human beings. It has not been elevated to a real reflective creation or a method of intellectual intuition. As a result, it cannot truly connect the self with Nature in order to illuminate the essence of Nature. I think advanced aesthetic activities are at the same level and have the same features as philosophical inquiries. It is most possible for humans to merge into an organic whole with Nature in such pure spiritual creative activities. The mechanism with its vertical and horizontal communication in simultaneous operation demonstrates the realization of the wondrous creation of Nature in the human soul. Therefore, arts and artistic criticism are the same as philosophy in terms of being a kind of spiritual practical activity with ultimate 
inquiries. From the perspective of humans, art has subjective objectivity; from the angle of Nature, art is creation of the subject with objectivity. Only with such a transcendental vision can we make a judgment on advanced artistic works.

I have had the feeling that my discussion with Xiaomang is like opening up a wasteland. A larger land in front is to be reclaimed by us. The most exciting part of being a pioneer is none other than hearing the echoes of Nature in the hardship of cultivation. We have had such an experience and also foresee that finally we would be thoroughly unified with Nature someday. We will keep our discussion as a memorandum of our adventurous activities.

In the end, I want to thank my husband Lu Yong. It is he who compiled my conversation with Xiaomang into a book. The amount of work was, undoubtedly, tremendous.

Xinglongcheng, Beijing

October 28, 2010

This article was collected, as a foreword, into the book See the Abyss from the Sky: A Conversation on New Classicist Literature that was published by Shanghai Literature and Art Press in 2011.

(Translated by Liyan Shen) 